\title{
Coronavirus Disease 2019 Treatment: It is Time for Stewardship!
}

\author{
Prashant Nasa
}

\begin{abstract}
Keywords: Adverse drug reactions, Coronavirus disease 2019, Coronavirus disease 2019 pandemic, COVID pneumonia, Emergency department, Pharmacovigilance, Therapeutic option, Trigger tool.

Indian Journal of Critical Care Medicine (2020): 10.5005/jp-journals-10071-23622
\end{abstract}

The pandemic of coronavirus disease 2019 (COVID-19) has caught global medical fraternity unaware. The pandemic of this nature has a frenzied medical world with scientists and physicians alike under intense pressure from general public and/or politicians. There has not been a single class of anti-infectives, immunomodulators, or even natural therapies which remain untouched in the treatment of COVID-19.

There is no approved drug till date (September 10, 2020) by United States-Food and Drug administration (US-FDA) for the prevention or treatment of COVID-19. ${ }^{1}$ The regular process of development and approval of a new drug would have taken months to years, scientists and regulatory bodies have taken faster route in this case of approving on trial basis the available drugs. This has brought to limelight the unpopular terminology in drug approvals like "off-label" or "compassionate use" which have been an ongoing debate in research ethics ${ }^{2-5}$ (Table 1 ).

The off-label drug is defined as a use of an approved medication in a dose, formulation, disease, or in a different patient population that does not have current FDA approval. ${ }^{2}$ The use of amiodarone for the treatment of supraventricular tachycardia or erythromycin for gastroparesis are few examples of off-label drugs in intensive care unit (ICU). The problem with off-label use of a drug is either none or insufficient scientific data on safety and efficacy. 2,6,7

In this issue of the journal, Maddani et al. conducted a multicentric survey from May 3 to June 10, 2020 to understand awareness and practice among treating physicians regarding COVID-19 treatment modalities. ${ }^{8}$ The survey timing coincided with start of the upsurge of cases in India. Clinicians were updated about the various therapeutics being tried in COVID-19, but awareness about side effects of medications and drug interactions was found inadequate. Hydroxychloroquine (HCQ) and lopinavir/ritonavir are some off-label drugs that are being used in COVID-19. No randomized study has showed any outcome benefit with HCQ and lopinavir/ritonavir. World Health Organization (WHO) stopped HCQ and lopinavir/ritonavir arm from Solidarity Trial on July 4, 2020. ${ }^{9}$ US-FDA issued a safety alert in relation to cardiac toxicity of HCQ and chloroquine on April 24, 2020 and withdrew its emergency use authorization (EUA) on June 15, 2020.10 In India, the HCQ has been withdrawn from treatment guidelines for the management of severe COVID-19 case. ${ }^{11}$

Compassionate use is another way of accessing these drugs for the treatment of patients with COVID-19 (Table 1). The compassionate use can be defined as an access to investigational drug out of clinical trial in specific situations (life-threatening disease or disease causing serious permanent disability), in the absence of any suitable alternative treatment. Ministry of Health and Family Welfare (MOHFW) proposed an amendment in June
Department of Critical Care Medicine, NMC Specialty Hospital, Dubai, UAE

Corresponding Author: Prashant Nasa, Department of Critical Care Medicine, NMC Specialty Hospital, Dubai, UAE, Phone: +971501425022, e-mail: dr.prashantnasa@hotmail.com

How to cite this article: Nasa P. Coronavirus Disease 2019 Treatment: It is Time for Stewardship! Indian J Crit Care Med 2020;24(10):895-896.

Source of support: Nil

Conflict of interest: None

2020 in the New Drug and Clinical Trial Rules, 2019 on import and prescription of compassionate drug use. ${ }^{12}$ The drug for this purpose must be under phase III clinical trial either within India or any other country. The "expanded access" is used interchangeably for compassionate use of a drug especially in the US.

Expanded access of a drug or product must meet the following criteria:

- Presence of a serious life-threatening disease or condition in a patient.

- There is no comparable alternative therapy available for the disease or condition.

- Patient cannot be enrolled in a clinical trial.

- Potential or known benefit outweighs the potential or known risks of treatment, and finally.

- Providing the investigational drug will not interfere with ongoing investigational trials.

\section{Emergency Use Authorization}

Emergency use authorization (EUA) is defined as temporarily authorization of a drug for a new indication or approving a previously unapproved drug out of normal process from the FDA in response to a security, military, or public health emergency. Severe acute respiratory syndrome coronavirus 2 (SARS-CoV-2) diagnostic kits, mechanical ventilators, personal protective equipment (PPE), and HCQ were few items which got EUA in COVID-19 pandemic by US-FDA. The EUA and compassionate use are not same, as the disease is not immediate life-threatening to a particular patient. However, the clinicians sometime erroneously use these terms interchangeably.

Remdesivir is allowed by MOHWF under EUA in India for the treatment of patients with moderate-to-severe COVID-19. The currently available evidence shows remdesivir shortens the recovery time but does not reduce mortality. The drug is costly 
Table 1: Different routes of access of drugs in coronavirus disease 2019

\begin{tabular}{|c|c|c|c|}
\hline & Off-label use & Compassionate use & Investigational use \\
\hline Definition & $\begin{array}{l}\text { Use of a drug in a disease or condi- } \\
\text { tion other than the one for which } \\
\text { it is approved. }\end{array}$ & $\begin{array}{l}\text { Use of a drug out of clinical trial in a life- } \\
\text { threatening or seriously debilitating disease } \\
\text { or condition and patient cannot be enrolled in } \\
\text { clinical trial }\end{array}$ & $\begin{array}{l}\text { Use of drug under clinical } \\
\text { trial for demonstration of } \\
\text { safety and efficacy }\end{array}$ \\
\hline Alternative names & $\begin{array}{l}\text { Unapproved use of an approved } \\
\text { drug }\end{array}$ & $\begin{array}{l}\text { Expanded access; preapproval access; special } \\
\text { access; early access }\end{array}$ & Trial drug \\
\hline Disease/condition & $\begin{array}{l}\text { Any disease/condition where drug } \\
\text { is not approved }\end{array}$ & $\begin{array}{l}\text { Life threatening or can cause severe perma- } \\
\text { nent disability }\end{array}$ & Any disease/condition \\
\hline IRB/EC approval & $\begin{array}{l}\text { Not required unless mandated by } \\
\text { the hospital }\end{array}$ & Required & Required \\
\hline Informed patient consent & Not required & Required & Required \\
\hline \multirow[t]{3}{*}{ Examples } & Hydroxychloroquine & Remdesivir & Hydroxychloroquine* \\
\hline & Azithromycin & Convalescent plasma & Convalescent plasma* \\
\hline & Lopinavir/ritonavir & & BCG (for prevention)* \\
\hline
\end{tabular}

*Under ongoing trials registered with Clinical Trial Registry of India (CTRI)

COVID-19, coronavirus disease-2019; IRB, Institutional Review Board; EC, Ethics Committee

and like other drugs has side effects. Remdesivir besides its gastrointestinal side effects (e.g., nausea, vomiting) can cause elevation of hepatic transaminase and prothrombin time [with no change in international normalized ratio (INR)]. Remdesivir also has drug interactions with rifampicin, $\mathrm{HCQ}$, and chloroquine and coadministration of these medications is not recommended.

The evidence on therapeutics in COVID-19 is emerging rapidly and clinicians must remain abreast with new trials. The offlabel or compassionate use of drugs can be compared to a new therapeutic procedure without proven safety and efficacy, hence need appropriate planning, informed consent, and monitoring of adverse events or outcomes. These drugs cannot be considered as "standard of care" instead should be used after appropriate patient selection, risk-benefit ratio assessment, and monitoring of any adverse effects with collective decision-making involving patient or next of kin. The primary responsibility of a clinician while treating a patient is "primum non nocere".

\section{References}

1. COVID-19-Related Guidance Documents for Industry, FDA Staff, and Other Stakeholders, Updated September 14, 2020. Available at: https://www.fda.gov/emergency-preparedness-and-response/ coronavirus-disease-2019-covid-19/covid-19-related-guidancedocuments-industry-fda-staff-and-other-stakeholders (accessed on 21st September 2020).

2. Wittich CM, Burkle CM, Lanier WL. Ten common questions (and their answers) about off-label drug use. Mayo Clin Proc 2012;87(10):982990. DOI: 10.1016/j.mayocp.2012.04.017.

3. Le Jeunne C, Billon N, Dandon A, Berdaï D, Adgibi Y, Bergmann JF, et al. Off-label prescriptions: how to identify them, frame them, announce them and monitor them in practice? Therapie 2013;68(4):225-239. DOI: $10.2515 /$ therapie/2013041.

4. Bunnik EM, Aarts N, van de Vathorst S. Little to lose and no other options: ethical issues in efforts to facilitate expanded access to investigational drugs. Health Policy 2018;122(9):977-983. DOI: 10.1016/j.healthpol.2018.06.005.

5. Goyal PK, Mathur R, Medhi B. Understanding the challenges and ethical aspects of compassionate use of drugs in emergency situations. Indian J Pharmacol 2020;52(3):163-171. DOI: 10.4103/ijp. IJP_665_20.

6. Gota V, Divatia JV. Off-label use of drugs: An evil or a necessity? Indian J Anaesth 2015;59(12):767-768. DOI: 10.4103/0019-5049.171555.

7. Oberoi SS. Regulating off-label drug use in india: the arena for concern. Perspect Clin Res 2015;6(3):129-133. DOI: 10.4103/22293485.159935.

8. Maddani SS, Chaudhuri S, Deepa HC, Amara V. A multicenter questionnaire-based study to know the awareness and medical treatment plan of physicians involved in the management of COVID19 patients. Indian J Crit Care Med 2020;24(10):919-925.

9. World Health Organization, "Solidarity" clinical trial for COVID-19 treatments. WHO. Available at https://www.who.int/emergencies/ diseases/novel-coronavirus-2019/global-research-on-novelcoronavirus-2019-ncov/solidarity-clinical-trial-for-covid-19treatments 2020 Jul 06; Accessed: July 6, 2020.

10. FDA cautions against use of hydroxychloroquine or chloroquine for COVID-19 outside of the hospital setting or a clinical trial due to risk of heart rhythm problems. US Food \& Drug Administration. 2020. Available at https://www.fda.gov/drugs/drug-safety-and-availability/ fda-cautions-against-use-hydroxychloroquine-or-chloroquinecovid-19-outside-hospital-setting-or.

11. Clinical management protocol:COVD-19. Government of India Ministry of Health and Family Welfare Directorate General of Health Services. Updated 3rd July 2020. Available at: https://www.mohfw.gov.in/pdf/ UpdatedClinicalManagementProtocolforCOVID19dated03072020. pdf (accessed on 21st September 2020).

12. Ministry of Health \&Family Welfare. The Gazatte of India: Extraordinary. 2020. Jun, 6, pp. 1-22. Available from: https://cdscogovin/opencms/ opencms/en/Notifications/Gazette-Notifications/ (accessed on 21st September 2020). 